\title{
Driving Mobile Game Engagement: Factors and User Metrics
}

\author{
Namira Chaldea \\ Faculty of Economy and Business, Department Magister \\ Management \\ Universitas Indonesia \\ Jakarta, Indonesia \\ nchaldea@gmail.com
}

\author{
Rambat Lupiyoadi \\ Faculty of Economy and Busines, Department Magister \\ Management \\ Universitas Indonesia \\ Jakarta, Indonesia \\ rambat_1@yahoo.com
}

\begin{abstract}
This study aims to identify methods to drive engagement with a mobile game by exploring the factors that affect engagement through a literature review and in-depth interviews with experts, and applying Exploratory Factor Analysis. The data are collected from a survey of mobile game players of CV.X, a casual idle clicker game. This study finds our factors of engagement: aesthetics, felt involvement, game mechanics, and endurability. Managers can improve players' engagement by creating an aesthetic aimed for usability of the game, having customization options, creating a cycle of goals and achievement to keep players interested, and creating mechanics that are interesting but not limited to unique and new designs.
\end{abstract}

Keywords—engagement, freemium, mobile game

\section{INTRODUCTION}

The need to be sustainable is high in the mobile game industry given the current landscape. The gamer population of 2.2 billion worldwide is expected to generate $\$ 108.9$ billion in revenues in 2017 [1]. Although lucrative, out of all the games available in the iOS AppStore in 2015, only 1,436 titles generate revenue more than $\$ 1$ million. Out of those, only $1.8 \%$ of the games generate more than $\$ 100$ million and $87 \%$ of the games generate $\$ 1-10$ million [2]. This indicates high competition to obtain a small portion of the mobile game market share.

In a business where revenues are generated from valueadded services and not the main product itself, it is vital to convert users who are playing for free to become paid users that purchase the game. According to SurveyMonkey Intelligence insight on Supercell's hit mobile game Boom Beach, there is a positive correlation between engagement and revenue. It is believed that engaged users spend more time in the game and are more likely to make purchases [3].

Although engagement is acknowledged as an important metric in the gaming industry, there is no clear consensus on the factors that drive the engagement. This is because engagement is tied to the core of the product, the game itself. The difference in design and the associated player data are immense; e.g., comparing Supercell's Clash of Clans with King's Candy Crush Saga. The player behavior and demography that these games generate are widely different even though they are both mobile games.

Previous studies have tried to identify the driving factors of engagement in e-commerce [4]; however, there is still no specific study on the factors of engagement for mobile games. In a new and growing market like mobile games, it is important to understand the factors of engagement that can create a sustainable game to be able to grow the business and, on a larger scale, the industry. With the ever-growing technology and the internet, the knowledge discovery process describing the journey from raw, untreated data to actionable insights is still a challenge [5]. This study aims to shed light on the factors and driving forces of engagement in a mobile game in order to turn them into insights for decision making that can create a sustainable game.

\section{A. Analytical Framework}

\section{1) Engagement in Mobile Games}

Engagement in a mobile game is like customer engagement behavior for other products. According to Van Doorn et al. [6], customer engagement behavior in a customer-to-firm relationship focuses on behavioral aspects of the relationship. In the mobile game context, customer engagement occurs when the customer realizes value from the product or, according to Schoenau-Fog [7], when a player becomes "hooked" and so entertained by the game that they want to continue playing. For differentiation purposes, the mobile game version of customer engagement behavior will be called "player engagement."

What differentiates player engagement from engagement in other products is how it intersects with the gameplay. This means factors that drive player engagement in one game may differ from another game; thus, a framework is needed to guide a developer to identify those unique facts. Previous studies have measured player engagement from a psychological point of view using instruments such as the game engagement questionnaire [8], which applies a user engagement scale that evaluates the human-computer interaction [9]. To enable the 
identification of factors of engagement, this study will take components from studies that are the most relevant to formulate the model.

The data in this study were collected using the Game Engagement Questionnaire [8], which is an instrument that examines how engagement affects the impacts of playing a game. The study identifies players' level of psychological engagement in playing video games, with the assumption that more engagement leads to a bigger impact from playing the game. The results show that a higher level of engagement leads to greater endorsement of the game from the player.

\section{2) User Engagement Scale}

The user engagement scale, which measures engagement in the context of e-commerce, was created by O'Brian and Toms [9]. In their previous research [4] on engagement in e-commerce, including video games, it is identified that there are four essential attributes of engagement: well-defined goals, immediate feedback from the system, prior experience, and increasing challenge in proportion to game playing skills. The research also mentioned physiological arousal, a player's sense of social presence, and sensation-seeking as factors of engagement in a video game.

Based on their previous research, O'Brian and Toms developed an instrument to measure engagement by using a questionnaire designed around six components linked to a person's engagement toward a product in an e-commerce context: Focused Attention, Perceived Usability, Aesthetics, Endurability, Novelty, and Felt Involvement.

Eric et al. (2013) applied the User Engagement Scale in the context of video games. That research concluded that games have four factors of engagement and that three of them are aligned with the subscales of the User Engagement Scale: Perceived Usability, Focused Attention, Aesthetics, Novelty, Endurability, and Felt Involvement. The fourth factor was the new finding of the study, called "Satisfaction." The name was chosen because the items that load against this scale relate closely to self-reported reflection on the more hedonistic aspects of their experience. This factor also correspond with O'Brien and Toms' (2012) findings, which further prove that Endurability, Novelty, and Felt Involvement should be considered as a single construct in the context of tasks such as games and online shopping.

Using this model as a base, the authors will give context to a mobile game industry specifically and compare the metrics that are found in game analytics in order to turn them into insights that can be used to create a sustainable game.

\section{METHOD}

For this research, the authors employed a two-stage approach to develop a reliable and valid instrument that is able to identify and measure variables that affect engagement in a mobile game. First, in-depth interviews were conducted with CV.X's project manager, who assisted in creating the instrument items required by the research problem. The next stage was a web-based questionnaire survey collected from players of the studied game based on the instrument created. Both stages will be supported by records, data, and information from the company's previous games.

\section{A. Case Study Overview}

To pinpoint the method to find key variables that affect engagement in a game, a case study approach is necessary. Because engagement in a game differs with each title, a case study to look at a specific game is a good way to find methods that is strongly connected to the core of the game, the gameplay. For this research, the authors analyzed the game of CV.X, an Indonesian game developer focused on making mobile games. The company was established in 2013, achieving success on their 20th game, with one million downloads in the first month and since then has accumulated 8 million downloads. Their most recent game, the focus of this study, is the company's first leap into the global market.

To further understand the game, the authors retrieved data from the studied game's game design document, a document that is used when designing a game and that includes the background, the mechanics, and the technical parts of the game. The studied game is an idle clicker game, i.e., you get small rewards every time you do a small action (of tapping). The premise of the game is where you build a coffee shop where each tap gives you a customer that will buy the coffee and generate revenue. However, customers will also come automatically in a period of time, creating a passive income. The revenue generated can then be used to upgrade items for your shop, increasing the effect of each customer and/or passive income. The ultimate goal of the game is to manage your store to create the most revenue by upgrading items for your shop.

\section{B. In-depth Interviews}

The authors conducted three separate interviews with CV.X's project manager of the studied game, with a twoday break between each session. The interviews each lasted approximately half an hour and were conducted in a comfortable and relaxing atmosphere. The interview guide comprised eight semi-structured questions with the first asking the project manager about engagement in a global context, in mobile games and then, more specifically, in the studied game. The final questions asked about variables presented in the User Engagement Scale in the context of mobile game. Most questions concerned the factors that affect the engagement of a mobile game, how important the 
engagement is, and how the company implements and calculates these factors in their decision making process.

There are several interesting and important facts revealed during the in-depth interviews that pertain to this research. The most striking is that the level of engagement varies among different games, creating no generalized factor of engagement. This statement is consistent with Evan's research (2015), which states that the business models are suited to the forms of gameplay mechanics such that each game is unique. With this statement, it can be assumed that in the industry itself, engagement is measured by factors that are dependent to the game they are developing, i.e., no general factors of engagement. The next information is connected to the first statement that is engagement is tightly linked to the gameplay of the game as it is stated that engagement in the mobile game context is "how much the players like the game in the context of how they play the game." This implies that in order to find the factors, we need to include game mechanics specific to the studied game. However, because of this statement, it is necessary for the author to use a base theory in order to find out the factors of engagement.

It is also stated in the interview that engagement is important for all types of games, not only freemium mobile. However, the importance is more significant in mobile games as it is a key factor in obtaining revenue for the developers, given the business model. Because this factor is important, there is already an analytics tool in the industry to measure engagement. This is basically the "factors" that the project manager of CV.X refers to as factors of engagement. These tools have a general method to measure engagement that includes retention (amount of people who return to play the game the following day), how long the players play the game, how many times they open the game in a day, and the data volume or Daily Active Users, Weekly Active Users, and Monthly Active Users. This can be the base engagement metric to be compared with the results of this research.

\section{Engagement Factors}

O'Brien and Toms stated in their previous study that the User Engagement Scale is composed of six distinct factors: Perceived Usability, Focused Attention, Aesthetics, Novelty, Endurability, and Felt Involvement. Presented below are the variables of engagement that the author has identified based on the User Engagement Scale, with the context added from the interview to create an instrument suitable to the mobile game context.

\section{- Focused Attention}

In a game, Focused Attention is the level of attention the gameplay mechanics create that makes a player become so focused in a game that it affects their perceptions of time. According to Schell [10] game mechanics are the procedures and rules of your game. Mechanics describe the goal of your game, how players can and cannot try to achieve it, and what happens when they try. Based on this, the authors conclude that this variable consists of the action a player needs to do in the game that requires manual input without taking your eyes off the screen.

\section{- Perceived Usability}

This variable is derived from the perceived usability variable of O'Brien and Toms' [4] research. After the interview with CV.X's project manager, it is established that the variable is like the user experience in a game. Moreover, the relationship between usability and user experience is intertwined as stated by Vermeeren et al. [11] in his study of User Experience. According to Hassenzahl [12], user experience is just a subcategory of experience, focusing on a particular mediator, namely, interactive products. It is tightly linked with the design of the user interface such as button positions, how the menu flows, and how easy it is to navigate through the game. CV.X's project manager adds that an important part of engagement is to make the users engage the first time they play and the first experience is the tutorial as it guides them on how to play the game. If a tutorial fails to tell the user how to play the game, then they will perceive that the usability of the game is bad; thus, the tutorial is an integral factor in enhancing the Perceived Usability.

\section{- Aesthetics}

Aesthetics is how the visuals of the game can stimulate the players to be more engaged in the game. According to Niedenthal [13], the aesthetics of a game refers to three kinds of experience: the sensory phenomena or visual stimuli the player encounters in a game and that relates to the way a game looks, sounds, and presents itself to the player; the artistic aspect of the game as the games are considered as a form of art that can be enjoyed the same as enjoying paintings in a museum; and the experience the player feels when playing a game or, as Kirkpatrick [14] describes it, "the play of imaginative and cognitive faculties."

\section{- Novelty}

The users' level of interest in the task and curiosity evoked by the system and its contents is called "novelty" [9]. In the context of mobile games, this variable is the curiosity evoked by the gameplay of the game, i.e., how much it can make the task intriguing to the player. As in Schoenau-Fog's [7] research, the objective and accomplishment variable, a key component in this is the goal of the game, its rewards, and the achievements a player gets when finishing a task. 
- Felt Involvement

The user's feelings of being drawn into the game and having fun during the interaction contribute to their Felt Involvement. For a game, it can be interpreted as the gameplay mechanics and how much the game gives the user freedom to customize the experience. Thus, involvement in a game is how much the player can influence the game and make the experience their own. For the studied game, it will be the availability of customization, the feeling of having their own shop, and the ability to get higher revenue for the shop. According to Bercu (2016) there are three components of involvement or, in this paper's terms, immersion of a player, discovery, role-playing, and customization, which give the user a chance to mirror his imagination of himself inside the game.

- Endurability

Endurability is the user's willingness to return to the product and recommend it to others. It is the sum of a user's felt experience after playing a game that stimulates the urge to play more [9]. According to the study, this is hypothesized to be the dependent factor that is ultimately influenced by other factors. The user's willingness to return is represented by "retention" in this study.

\section{Conducting the Survey}

The web-based survey was conducted using Google's Google Forms. Because the largest demographic of the game's revenue comes from Indonesia and the U.S., there were two Google Forms, one in Indonesian and one in English. The survey contained three sections. In the survey, instructions are positioned at the top of the page of each section. a progress bar is present at the bottom to indicate their proximity to completion: the first section contains introductory and informed consent information; Section 2 consisted of interval level measurement of agree and disagreement; Section 3 presented a semantic differential approach of the level measurement; and the Concluding Page thanked respondents for their participation. A voucher for the game was issued at the end of the survey and participants could redeem it for a limited edition Christmas decoration for their online stall. The survey was distributed through the game platform on the news tab with a button that linked to the survey. Depending on the language (English or Indonesian) the button returned the respective survey.

\section{RESULTS AND DISCUSSION}

The survey generated 200 responses, which is an adequate sample for analysis. The data analysis included:

\section{An assessment of data reliability}

2. Performing exploratory factor analysis (EFA) is performed to asses the validity of the construct and the factor's nature.
The data were collected within three weeks of posting the survey on the game's news tab. A demographic profile of the respondents is presented in Table 1 . It can be noted that a higher percentage of males play the game in Indonesia than in the U.S., which has a higher percentage of older players than Indonesia.

TABLE I. RESPONDENT PRofILE

\begin{tabular}{|c|c|c|c|}
\hline \multicolumn{2}{|l|}{ Variable } & \multirow{2}{*}{$\begin{array}{l}\text { Frequency } \\
122\end{array}$} & \multirow{2}{*}{$\begin{array}{l}\text { Percentage } \\
61 \%\end{array}$} \\
\hline Geooranhica & Indonesia & & \\
\hline & United States & 78 & $39 \%$ \\
\hline \multirow{3}{*}{ Gender } & Male & 114 & $57 \%$ \\
\hline & Female & 80 & $40 \%$ \\
\hline & Do not specify & 6 & $3 \%$ \\
\hline \multirow{3}{*}{$\begin{array}{l}\text { Gender } \\
\text { (United States) }\end{array}$} & Male & 41 & $52.5 \%$ \\
\hline & Female & 32 & $41 \%$ \\
\hline & Do not specify & 5 & $6.5 \%$ \\
\hline \multirow{3}{*}{$\begin{array}{l}\text { Gender } \\
\text { (Indonesia) }\end{array}$} & Male & 73 & $59.9 \%$ \\
\hline & Female & 48 & $39.3 \%$ \\
\hline & Do not specify & 1 & $0.8 \%$ \\
\hline \multirow{5}{*}{ Age (years) } & Under 12 & 25 & $12.5 \%$ \\
\hline & $12-17$ & 69 & $34.5 \%$ \\
\hline & $18-24$ & 67 & $33.5 \%$ \\
\hline & $25-34$ & 32 & $16 \%$ \\
\hline & Over 34 & 7 & $3.5 \%$ \\
\hline \multirow{5}{*}{$\begin{array}{l}\text { Age: United States } \\
\text { (years) }\end{array}$} & Under 12 & 3 & $3.8 \%$ \\
\hline & $12-17$ & 23 & $29.5 \%$ \\
\hline & $18-24$ & 31 & $39.7 \%$ \\
\hline & $25-34$ & 17 & $21.8 \%$ \\
\hline & Over 34 & 4 & $5.2 \%$ \\
\hline \multirow{5}{*}{ Age: Indonesia (years) } & Under 12 & 22 & $18 \%$ \\
\hline & $12-17$ & 46 & $37.7 \%$ \\
\hline & $18-24$ & 36 & $29.5 \%$ \\
\hline & $25-34$ & 15 & $12.3 \%$ \\
\hline & Over 34 & 3 & $2.5 \%$ \\
\hline
\end{tabular}

(Source: Survey data) 


\section{A. Descriptive Statistics}

Table 2 shows the descriptive statistics of the respondent data, displaying the mean, standard deviation, and the range.

TABLE II. DESCRIPTIVE STATISTICS

\begin{tabular}{|l|l|l|l|l|}
\hline Variables & $\boldsymbol{n}$ & Mean & $\begin{array}{l}\text { Std } \\
\text { Deviation }\end{array}$ & Range \\
\hline Enjoyment & 200 & 4.38 & 0.65 & 2 \\
\hline Goal time & 200 & 3.92 & 0.93 & 4 \\
\hline Upgrade time & 200 & 4.01 & 0.95 & 4 \\
\hline Decorate time & 200 & 3.13 & 1.30 & 4 \\
\hline Navigation & 200 & 4.04 & 1.00 & 4 \\
\hline Tutorial & 200 & 4.52 & 0.78 & 3 \\
\hline Learning & 200 & 4.49 & 0.73 & 3 \\
\hline Art style & 200 & 4.52 & 0.78 & 3 \\
\hline Art influence & 200 & 4.20 & 0.87 & 3 \\
\hline Art decision & 200 & 3.68 & 1.23 & 4 \\
\hline Game interest & 200 & 3.96 & 0.90 & 4 \\
\hline Completion & 200 & 4.38 & 0.87 & 4 \\
\hline Story & 200 & 4.21 & 0.92 & 4 \\
\hline Decoration & 200 & 3.37 & 1.29 & 4 \\
\hline Read story & 200 & 4.19 & 1.08 & 4 \\
\hline Resource management & 200 & 4.24 & 0.91 & 4 \\
\hline Ownership & 200 & 3.97 & 1.19 & 4 \\
\hline Like & 200 & 4.47 & 0.70 & 3 \\
\hline Recommend & 200 & 3.55 & 1.16 & 4 \\
\hline Play time & 4.16 & 0.87 & 3 \\
\hline
\end{tabular}

\section{B. Exploratory Factor Analysis}

EFA is the method selected because identifying the most fitting set of items is the outcome of this analysis and to be able to maximize the variance that are extracted. Using the Kaiser-Meyer-Olkin (KMO) test, the measure of sampling adequacy $(\mathrm{KMO}=0.865)$ indicates that the factor analysis will result in distinct and reliable factors. The relationships was verified with Bartlett's test of sphericity $(\chi 2=1877.605, \mathrm{df}=190, p<0.001)$, which means there are relationships among the items.

The author used the most common rotational technique, the varimax rotation, to simplify the factors. Comrey and Lee's (1992, as cited in Tabachnick \& Fidell) criteria was used to interpret the item loadings:

- 0.71 or greater (between variable and factor have $50 \%$ overlapping variance): excellent;

- 0.63 or greater (between variable and factor have $40 \%$ overlapping variance): very good;

- 0.55 or greater (between variable and factor have $30 \%$ overlapping variance): good;

- 0.45 or greater (between variable and factor have $20 \%$ overlapping variance): fair;

- 0.32 (between variable and factor have $10 \%$ overlapping variance): poor.

To be conservative, the cutoff value selected is 0.45 . Ten iterations of factor analysis were performed. Each iteration, we eliminate the factors that have loaded strongly on multiple factor. At the end of the tenth iteration, four factors and ten subscales remained.. Table 4.4 shows the simplified results of the factor analysis simplified. Subscale factors with values below 0.45 are not mentioned in order to emphasize the factor loadings.

TABLE III.

EXPLORATORY FACTOR ANALYSIS RESULTS

\begin{tabular}{|l|l|l|l|l|}
\hline & Game Mechanics & Endurability & Aesthetics & Felt Involvement \\
\hline Story & 0.564 & & & \\
\hline Read story & 0.589 & & & \\
\hline Resource management & 0.658 & & & \\
\hline Navigation & 0.663 & & & \\
\hline Tutorial & 0.602 & & & \\
\hline
\end{tabular}


Continue: TABLE III. EXPLORATORY FACTOR ANALYSIS RESULTS

\begin{tabular}{|l|l|l|l|l|}
\hline & Game Mechanics & Endurability & Aesthetics & Felt Involvement \\
\hline Learning & 0.730 & & & \\
\hline Enjoyment & & 0.674 & & \\
\hline Like & & 0.733 & & \\
\hline Recommend & & 0.471 & & \\
\hline Play time & & 0.693 & & \\
\hline Game interest & & 0.527 & & \\
\hline Decorate time & & & 0.756 & \\
\hline Decoration & & & 0.779 & \\
\hline Art style & & & 0.562 & \\
\hline Art influence & & & 0.577 & \\
\hline Art decision & & & 0.618 & \\
\hline Completion & & & & \\
\hline Goal time & & & & 0.512 \\
\hline Upgrade time & & & & 0.704 \\
\hline
\end{tabular}

The analysis identifies the factors of engagement using a survey with 200 participants from Indonesia and the U.S. region, calculating 20 items. The data were then tested to determine if EFA is suitable for this research. The results show that the KMO measuring of sampling adequacy will result in reliable and distinct factors, and the relationship was verified with Bartlett's test of sphericity. The data were then analyzed using EFA with the varimax rotation, creating 10 iterations. At the end of the tenth iteration, four factors and ten subscales remained. The factors were interpreted and labeled as Game Mechanics (Factor 1), Endurability (Factor 2), Aesthetics (Factor 3), and Felt Involvement (Factor 4).

\section{Analysis}

The findings of previous studies were the foundation for this study and helped construct a multidimensional scale to measure user engagement in a mobile game. In this section, the author will provide a thorough analysis based on the results of EFA and connect them to the context of the industry to make them more applicable.
Engagement is a crucial factor in the mobile game industry to create sustainability. In this research, the author first identified factors of engagement from previous studies, using the User Engagement Scale as the basis. Initially, six factors affecting engagement were proposed: Novelty, Aesthetics, Immersion, Absorption, User Experience, and Retainability. After testing the variables through subscales and using EFA, only four factors remained: Aesthetics, Absorption, Game Mechanics, and Retainability.

Aesthetics was hypothesized to not affect engagement directly, but rather to play a role in creating engagement. Previous studies define this variable as the visual elements of the product (Wiebe et al., 2013) or the visual beauty [9]. However, the EFA result shows that there can be more than the visual elements created by the developers of the game, but also those that come from the players themselves with the help of customization. This is evident from the subscale added to this factor (i.e., Decoration), which refers to the mechanics in the game that allow the player to customize how the game looks according to their taste. In other words, more engagement can be achieved by allowing players to 
take part in creating the visuals or aesthetics that they like. This statement aligns with the finding in Turkay and Adinolf's [15] study that customization affects massively multiplayer online (MMO) game players' enjoyment to a moderate or large degree.

Felt Involvement is a factor derived from the study of flow and pertains to the "loss of time" aspect that players feel when they are absorbed in the game [16]. Through EFA, there was an addition of the subscale Completion to this variable. This signifies the feeling of accomplishment when finishing an objective. This also means that absorption not only comes from the gameplay mechanics but also the set objectives. The result confirms that clear goals create enjoyment [17]. A phenomenon that corroborates this statement can be seen in recent games that introduce a "daily quest feature" that gives players objectives to complete every day and thereby creates a feeling of accomplishment.

The Game Mechanics variable is a combination of subscales from the three variables, Immersion, User Experience, and Novelty. Although the three variables seem different, the subscales all linked to Game Mechanics (the procedures and rules of the game) [10], and was named thus. This factor can be a unique factor that can only be used in a freemium game context because it combines the usability of the game with the game mechanics. Evans (2015) states that game mechanics are utilized to intersect with the business aspect, which explains why the subscales of user experience are included with the same variable as Resource Management, the core game mechanic. The usability of the game must be seen as one and connected with the game mechanics to create more engaging experience for the players.

Although Endurability retains all its subscales, it adds two subscales from the variables Immersion and Absorption, which are Enjoyment and Game Interest. This corresponds to the findings of Wiebe et al. (2013) and O'Brien and Toms (2012) in which this type of subscale combination should be considered one single construct in the context of these kinds of task. the items that loads against this scales can be seen related closely to self reported reflection that is more on the hedonistic aspect of the experience. the items were those that is related to how novel and fun the experience was, and the likelihood that they would want to play/use this game again.

\section{CONCLUSION}

This study contributes to a further understanding of the measurement of engagement in mobile game-based environments The results of this research will benefit academicians and developers alike by identifying the factors of engagement and their relationships, enhancing their understanding of engagement, and providing a decision making framework to create more sustainable games. Furthermore, by incorporating such strategies to improve sustainability, businesses in the gaming industry can contribute to Indonesia's economy through the creative sector.

The following suggestions are aimed toward the general and strategic management of companies in the mobile game development industry. For managers to drive engagement, the authors suggest that engagement needs to be placed under consideration at the beginning of the development process because most of these factors relate directly to the game product. Although, mobile game is more agile and is refined through each iteration, games could already been made but needs the knowledge on improving engagement. By understanding the factors of engagement-absorption, aesthetics, game mechanics, and retainability-managers can identify ways to improve engagement in both current and future games.

It is further suggested that game aesthetics are considered carefully when developing a mobile game. Not to be confused with creating a subjective "beautiful and stunning visual," the design aspect should be emphasized as it affects the usability of the game and overall game mechanics. Furthermore, creating a mechanic where the player can customize the aesthetic of the game to suit their liking is recommended to further boost engagement.

Finally, the game as a package should include a good and easy way to understand user experience, a story that stimulates absorption of the player, and mechanics that are interesting to the player, which are not limited to unique and new mechanics. To increase the players' absorption, managers also need to emphasize the goals and achievements in the game itself in order to generate interest and the feeling of being "sucked in." One way to create engagement using goals and objective is to refresh the goals each time a player achieves an objective and create a cycle of engagement, for example, by creating daily quests that keep players engaged.

\section{A. Limitations and Future Research}

This work uses an online survey as a method of data collection thus it has limitations. Due to the nature of survey research, difference between those who did respond and who did not may create biases. Furthermore, due to the limited number of respondents (200), the results may reflect a larger margin of error in calculation. Using only one game as the focus of this research introduces biases and results of limited generalizability; however, it is necessary first to isolate the variables in this research.

Although this study failed to collect significant in-depth data to include a wider range of games, future works can help through examining the generalizability of the survey instruments with other games or examine the instrument in a larger context such as game genre or other game classification. The scope of user experience in a mobile game environment-whether it's designing for and 
measuring - is broad. This paper can be a foundation to perform further testing of the model and scale, build more dialogue about engagement, and examining other additional methods available to measure the attributes and their relationships.

\section{ACKNOWLEDGMENT}

The authors thank CV.X and their project manager for allowing us to use one of their projects to be the subject of this research. We would also like to thank University of Indonesia and the lecturers that help make this paper better as a research.

\section{REFERENCES}

[1] Chan, S. (2017, July 13). Mobile game revenue finally surpasses PC and consoles. Retrieved March 10, 2018. https://venturebeat.com/2017/07/13/mobile-game-revenuefinally-surpasses-pc-and-consoles/

[2] Digital App Economy Forecast: App Annie's App Monetization Report (2016, November 2). March 10,2018. https://www.appannie.com/en/insights/market-data/appmonetization-report-2016/

[3] Economides, N., \& Tag, J. (2012), "Network neutrality on the internet: a two-sided market analysis", Information Economics and Policy, Vol. 24 No. 2, pp. 91-104.

[4] Evans, E. (2016). The economics of free: Freemium games, branding and the impatience economy. Convergence, 22(6), 563-580.

[5] Sonders, M. (2016, December 8). Mobile App Engagement: Everything appdevelopers should know. March 10, 2018. https://medium.com/@sm app intel/mobile-appengagement-everything-app-deVelopers-should-knowecfede 043075

[6] O'Brien, H. L., \& Toms, E. G. (2008). What is user engagement? A conceptual framework for defining user engagement with technology. Journal of the American Society for Information Science and Technology, 59(6), 938-955.

[7] Drachen, A., El-Nasr, M. S., \& Canossa, A. (2013). Game analytics-the basics. In Game analytics (pp. 13-40). Springer, London.

[8] Van Doorn, J., Lemon, K. N., Mittal, V., Nass, S., Pick, D., Pirner, P., \& Verhoef, P. C. (2010). Customer engagement behavior: Theoretical foundations and research directions. Journal of service research, 13(3), 253-266.

[9] Sweetser, P., \& Johnson, D. (2004, September). Playercentered game environments: Assessing player opinions, experiences, and issues. In International Conference on Entertainment Computing (pp. 321-332). Springer, Berlin, Heidelberg.

[10] Schoenau-Fog, H. (2011, September). The Player Engagement Process-An Exploration of Continuation Desire in Digital Games. In DiGRA Conference.

[11] Brockmyer, J. H., Fox, C. M., Curtiss, K. A., McBroom, E., Burkhart, K. M., \& Pidruzny, J. N. (2009). The development of the Game Engagement Questionnaire: A measure of engagement in video game-playing. Journal of Experimental Social Psychology, 45(4), 624-634.

[12] O'Brien, H. L., \& Toms, E. G. (2010). The development and evaluation of a survey tomeasure user engagement. Journal of the Association for Information Science and Technology, 61(1), 50-69.

[13] Schell, J. (2014). The Art of Game Design: A book of lenses. AK Peters/CRC Press

[14] Vermeeren, A. P., Law, E. L. C., Roto, V., Obrist, M., Hoonhout, J., \& Väänänen-Vainio-Mattila, K. (2010, October). User experience evaluation methods: current state and development needs. In Proceedings of the 6th Nordic
Conference on Human-Computer Interaction: Extending Boundaries (pp. 521-530). ACM.

[15] Hassenzahl, M. (2013). User experience and experience design. The Encyclopedia of Human-Computer Interaction, .

[16] Niedenthal, S. (2009). What we talk about when we talk about game aesthetics.

[17] Kirkpatrick, G. (2007). Between art and gameness: Critical theory and computer game aesthetics. Thesis Eleven, 89(1), 7493.

[18] Turkay, S., \& Adinolf, S. (2010). Free to be me: a survey study on customization with World of Warcraft and City Of Heroes/Villains players. Procedia-Social and Behavioral Sciences, 2(2), 1840-1845.

[19] Csikszentmihalyi, M. (1990). Flow: The psychology of optimal performance. NY: Cambridge UniversityPress, 40.

[20] Sweetser, P., \& Wyeth, P. (2005). GameFlow: a model for evaluating player enjoyment in games. Computers in $\begin{array}{llll}\text { Entertainment } & (C I E), & 3(3),\end{array}$ 